\title{
"O caminho é aqui": um estudo antropológico da experiência do Caminho de Santiago de Compostela em uma associação de peregrinos do Rio Grande do Sul, Brasil ${ }^{1}$
}

\section{Rodrigo Toniol ${ }^{\mathrm{i}}$}

Universidade Federal do Rio Grande do Sul

\begin{abstract}
Resumo: O foco de interesse empírico deste trabalho são as atividades desenvolvidas pela Associação dos Amigos do Caminho de Santiago do Rio Grande do Sul (ACASARGS). Trata-se de uma organização sem fins lucrativos que visa promover e conservar o Caminho de Santiago de Compostela a partir da organização de caminhadas que procuram reproduzir, no interior do Rio Grande do Sul, as dificuldades e as distâncias diárias percorridas no Caminho espanhol. Problematizo, aqui, a perspectiva teórica que relaciona turismo com prática do não-cotidiano e apresento, a partir de uma narrativa etnográfica, o modo pelo qual as atividades da ACASARGS constituem-se, para os peregrinos, como eventos capazes de rotinizar a experiência da peregrinação no Caminho de Santiago mesmo fora da Espanha.
\end{abstract}

Palavras-Chave: Caminho de Santiago; Peregrinação; Turismo Religioso; Cotidiano; Communitas; Turismo

Title: "The way is here": Anthropological studies about St. James Way at Santiago de Compostela at a Pilgrims Society in Rio Grande do Sul State, Brazil

Abstract: This article focuses the activities of Friends of St. James Way in Rio Grande do Sul Association (ACASARGS) which is a nonprofit organization that aims to promote and preserve St. James Way at that Brazilian estate, in roads that reproduce the difficulties and the daily distances in the Spanish route. Discussing some theoretical approaches that relate tourism to the practice of nonroutine activities, through an ethnographic narrative I suggest that ACASARGS activities change pilgrimage experience at St. James way into a routine out of Spain.

Keywords: St. James Way; Pilgrimage; Religious Tourism; Uneventful; Communitas; Tourism

iMestrando em Antropologia Social pelo Programa de Pós-Graduação em Antropologia.

Email: rodrigo.toniol@gmail.com 


\section{Introdução}

Este artigo tem como foco de interesse empírico a prática de caminhadas na Associação dos Amigos do Caminho de Santiago do Rio Grande do Sul (ACASARGS). Trata-se de uma organização sem fins lucrativos que visa promover e conservar o Caminho de Santiago de Compostela a partir de caminhadas em percursos que reproduzem, no interior do Rio Grande do Sul - Brasil, as dificuldades e as distâncias diárias percorridas no Caminho. Soma-se a este aspecto a presença de uma série de elementos que remetem os peregrinos a Santiago, tais como: conversas, objetos usados na peregrinação, amuletos e conchas de vieira presas à mochila ${ }^{2}$. A partir deste contexto, procuro refletir sobre o modo pelo qual as caminhadas da ACASARGS realizadas no Brasil têm uma capacidade de subversão espaço-temporal reportando os peregrinos a experiências que, a priori, estavam acessíveis apenas no Caminho espanhol.

A partir da observação participante e de entrevistas realizadas com os sujeitos envolvidos nas caminhadas e noutras atividades da ACASARGS, procuro compreender como as caminhadas se constituem como uma espécie de rotinizadoras das experiências da peregrinação à Compostela, permitindo, assim, que se problematize a concepção de eventos turísticos como momentos do não-cotidiano. $\mathrm{O}$ que está em jogo é apresentar, desde uma perspectiva antropológica, como as experiências do Caminho de Santiago para os peregrinos não se definem a partir da feitura de um percurso num determinado território, mas, antes disso, no modo pelo qual os espaços são mobilizados subjetivamente de maneiras específicas.

A ordem de exposição deste texto apresenta, num primeiro momento, a popularização do Caminho de Santiago e o papel das Associações do Caminho neste processo. Noutro momento, apresento o panorama híbrido no qual o Caminho de Santiago se insere, explicitando uma série de sobreposições entre elementos como turismo, espiritualidade e mercado. Em uma terceira sessão, aponto para algumas perspectivas teóricas sobre turismo que associam este fenômeno com o não-cotidiano, bem como os desdobramentos destas perspectivas nas análises de peregrinações e turismo religioso. Noutra sessão, elaboro uma narrativa etnográfica na qual descrevo as táticas e estratégias das caminhadas da ACASARGS para "reproduzir" o Caminho de Santiago no Rio Grande do Sul, Brasil. Por fim, discuto aspectos relativos à prática do espaço dos sujeitos que caminham e que planejam a caminhada, articulando noções como paisagens, espaço e tempo.

\section{O Caminho de Santiago num contex- to de Nova Era: continuidades e rup- turas numa peregrinação cristã}

A raiz etimológica do termo "peregrinação" deriva do vocábulo latino peregrinus que significa

o estrangeiro, aquele que vive alhures

e que não pertence à sociedade autóc-

tone estabelecida, ou seja, é aquele que percorreu um espaço e, neste espaço, encontra o Outro (Dupront, 1987)

Tal acepção aponta para o encontro com "o Outro" como indicativo de um duplo aspecto. Por um lado, este encontro remete às dificuldades objetivas da jornada empreendida pelo peregrino que, ao percorrer lugares desconhecidos e enfrentar as adversidades do caminho, termina por imprimir nessa viagem características de uma jornada heróica. E, por outro, refere-se ao ato de transformação de si alcançado por meio de um deslocamento do "eu" em busca do "Outro", constituindo um percurso interior, de cunho místico e ascético, a ser realizado por aquele que peregrina (Toniol e Steil, 2010).

Nancy Frey, no livro "Pilgrim stories: on and off the road to Santiago" (1998), mostra como a peregrinação se inicia num período anterior a ida efetiva a Santiago. O movimento físico no Caminho é antecipado por uma espécie de movimento interno que convoca o peregrino a refletir sobre si, a colocar em questão seus "apegos" con- 
duzindo-o a decidir, por exemplo, o que levará na mochila durante os trinta e dois dias de caminhada. Sob certa perspectiva, aponta a autora, esta convocação ao "desapego" se apresenta aos sujeitos como um exercício não habitual, contrastivo com sua vida cotidiana. A utilização deste recurso que coloca em relevo oposições como cotidiano e não-cotidiano, trabalho e não-trabalho, ordinário e extraoridinário, para analisar e descrever práticas turísticas - sejam elas religiosas ou não tem sido freqüente entre os pesquisadores destes fenômenos (Smith, 1989; Graburn, 1989; Urry, 1990; Tuan, 1983).

Embora o "desapego" e a "viagem ao interior de si" sejam características marcantes das peregrinações cristãs, algumas propriedades distintivas do Caminho de Santiago transformam-no em um lócus privilegiado para se observar a incorporação, pelo catolicismo, de novas estruturas de sentido. $\mathrm{O}$ catolicismo, nesse caso, expande-se para além dos marcos dogmáticos e institucionais da Igreja Católica podendo, ao mesmo tempo, ter assegurada a sua continuidade a partir, justamente, da descontinuidade em relação à tradição e ortodoxia católicas. Semelhanças e dessemelhanças, permanências e modificações no âmbito do catolicismo não necessariamente operam como práticas excludentes, mas coexistem, contraditoriamente, em suas temporalidades diversas.

Nesse panorama, o Caminho de Santiago assume um papel ambivalente. A permanência de certas qualidades distintivas das peregrinações cristãs - "uma busca mística de si, como uma jornada de santificação que encontra seu ponto de chegada no reconhecimento de uma divindade que se manifesta no interior de cada devoto" (Steil, 2003) - também permite que essa mesma característica se modifique na experiência religiosa dos peregrinos associados a contextos culturais específicos. Grosso modo, apesar do termo não ser consensual, essas novas estruturas de sentido dizem respeito a práticas afinadas com certo "espírito Nova Era”.

A reapropriação do Caminho de San- tiago a partir desse contexto pode ser caracterizada, sobretudo, pela autonomização da experiência religiosa do peregrino frente a normalizações institucionais e pela busca pelo aperfeiçoamento de si. Processo que parece estar relacionado com uma transformação mais ampla do cenário religioso contemporâneo. Já a consagração do Caminho de Santiago ${ }^{3}$ como ícone dessas novas formas de relação com o sagrado, foi acompanhada pela produção de best-sellers ${ }^{4}$, documentários, somados a um oportunismo do mercado turístico que ajudaram a transformar a Rota Jacobea ${ }^{5}$ em um local emblemático entre aqueles que compartilham valores como culto ao corpo e valorização de experiências individuais.

\section{A popularização do "novo" Caminho de Santiago e suas Associações}

A popularização do Caminho de Santiago de Compostela pode ser expressa por meio de alguns números fornecidos pela Xunta da Galicia ${ }^{6}$ os quais nos mostram que no ano de 1986 o Caminho recebeu 1461 peregrinos, saltando dez anos mais tarde (1996) para 23.218 e atingindo, em 2004, a marca de 179.944 peregrinos (Carneiro, 2007). Somente em agosto de 2009, segundo números fornecidos pela oficina de peregrinaciones ${ }^{7}$, 35.071 peregrinos fizeram o Caminho de Santiago. Uma das causas dessa mudança foi o investimento do Ministério do Turismo do governo espanhol na criação, em todo mundo, das chamadas Associações dos Amigos do Caminho de Santiago - AACS (Carneiro, 2007).

No Brasil, essa organização sem fins lucrativos possui uma sede nacional no Rio de Janeiro, Associação Brasileira dos Amigos Caminho de Santiago (AACSB), e dezenas de filiais em todas as regiões do país. A AACSB estabelece diretrizes para as atividades de suas regionais tendo como missão promover o "encontro de pessoas e grupos interessados no percurso, na preservação e na divulgação do Caminho de Santiago de Compostela"8. Num documento que orienta as atividades das 
associações, a AACSB pontua: "Nossa ação voluntária, oferece elementos de ajuda e facilidades para que a peregrinação seja uma oportunidade de crescimento espiritual, cultural e comunitário. Estas ações acontecem, principalmente, através de palestras para futuros peregrinos, com orientações sobre a peregrinação, refúgios, equipamentos, saúde, comportamento, sinalização etc. Periodicamente realizamos caminhadas de condicionamento. Somos autorizados pela Oficina de $\mathrm{Pe}$ regrinos a emitir a Credencial do Peregrino, serviço que prestamos gratuitamente, sendo cobradas unicamente as despesas postais de remessa. Disponibilizamos, na Internet, um website - www. caminhodesantiago.org.br, com todas as informações necessárias para os peregrinos, o que permite aos residentes fora da área onde se localiza nossa sede, no Rio de Janeiro, acesso aos dados necessários para sua peregrinação, incluindo pesquisas constantes de preços mais acessíveis das passagens aéreas rumo à Espanha."

Além das facilidades direcionadas à peregrinação pelos Caminhos de Santiago, a AASC Brasil incentiva o conhecimento da sua história, cultura e a manutenção das tradições relacionadas com a Rota Jacobea:

Consideramos que devem ser mantidos os sentimentos de solidariedade, acolhida e de hospitalidade inerentes ao espírito das peregrinações compostelanas, principalmente nos refúgios onde os peregrinos descansam de sua jornada; e serem preservadas a arte, arquitetura e recursos naturais por onde atravessam as diversas rotas rumo à Santiago de Compostela. A Associação pretende desenvolver atividades e campanhas que minimizem as possibilidades de ações e usos não sustentáveis que possam afetar a integridade destes valores. Estamos associando nossas ações às pessoas físicas e jurídicas, nacionais e estrangeiras, principalmente às associações congêneres, no intuito de promover uma eficiente troca de informações direcionadas a maior atuali- zação possível das informações a serem fornecidas aos que estão se preparando para a peregrinação. ${ }^{10}$

De modo geral, as atividades das associações consistem na realização de caminhadas que reproduzem, em alguma medida, na paisagem, as dificuldades e as distâncias que o peregrino enfrentará diariamente enquanto estiver percorrendo os quase 800 quilômetros do Caminho ${ }^{11}$. Além de preparar aqueles que estão indo para Santiago, as AACS reúnem também, por meio de reuniões mensais e caminhadas periódicas de um dia, aqueles que já "fizeram" o Caminho.

Na cidade de Porto Alegre, capital do Rio Grande do Sul, a Associação dos Amigos do Caminho de Santiago do Rio Grande do Sul (ACASARGS) tem sua sede na Igreja Nossa Senhora da Piedade onde se realizam reuniões mensais voltadas tanto àqueles que irão à Santiago e que poderão, nesses encontros, receber dicas, como também àqueles que querem relatar ao grupo suas experiências no Caminho ${ }^{12}$. A ACASARGS também atua como uma espécie de agência autorizada do Caminho de Santiago, distribuindo a "Credencial do Peregrino", documento que será carimbado ao longo do trajeto em Santiago e comprovará a distância e os lugares percorridos. Além de ser um objeto de recordação e estima, a credencial também permite que o peregrino receba, na Igreja de Santiago, a Compostelana ${ }^{13}$.

Com uma agenda de uma caminhada por mês, que custam entre $R \$ 50$ a $R \$$ $70,00^{14}$, as atividades da ACASARGS reúnem por volta de quarenta participantes que se interam do cronograma dos eventos por meio de correio eletrônico, de um website $^{15}$ e de reuniões mensais. Para cada uma das caminhadas, constitui-se um grupo predominantemente composto por peregrinos que já fizeram o Caminho em idade entre quarenta e sessenta anos. A maior parte dessas atividades tem duração de um dia e ocorrem em cidades do entorno de Porto Alegre.

As caminhadas da ACASARGS podem ser descritas, genericamente, como extensas distâncias percorridas ao longo de 
um único dia, por grandes grupos numa estrada rural sinalizada com setas amarelas, como as existentes no Caminho de Santiago. Com essas marcações, a presença de guias que orientem a direção correta a ser tomada pode ser dispensada, permitindo, assim, que se caminhe sozinho - como a maior parte dos peregrinos faz em Santiago.

No estatuto de fundação da Associação gaúcha, o grupo define-se da seguinte maneira: "A ACASARGS, tem por objetivo e finalidade, a reunião de pessoas físicas, jurídicas e filantrópicas, que realizaram ou que manifestem interesse em conhecer, pesquisar ou fazer a peregrinação a Santiago de Compostela, na Espanha, promovendo a troca de informações e o intercâmbio cultural, sociológico e experimental, bem ainda, todo e qualquer subsídio ou material informativo que busque recriar culturalmente o Caminho de Santiago de Compostela, sob o ponto de vista histórico, religioso, artístico, arquitetônico e humanístico $^{16}$.

A ACASARGS constitui-se, assim, como uma espécie de representante oficial de tudo o que estiver relacionado à Compostela no Estado, atribuindo a si mesma as prerrogativas desse domínio e reforçando, em diversos âmbitos, sua posição. Em documento publicado pela Federação Espanhola das Associações dos Amigos do Caminho de Santiago, propõe-se que as Associações nacionais e locais se concebam como "consulados" do Caminho, devendo "sempre se manter atentas a grupos que pretendam desvirtuar os verdadeiros valores de Santiago"17.

\section{Turismo, espiritualidade e mercado entre os peregrinos}

A acepção de "turismo religioso" parece evidenciar-se na própria construção sintática do termo. O sentido "religioso" adjetiva o substantivo "turismo" dando a noção de um fenômeno que é, ao mesmo tempo, singular em suas características e comum a outros em sua forma. Carlos Steil (2003), em um esforço de distinção do que seja peregrinação, romaria e turismo religioso, afirma:

O termo turismo religioso possui uma conotação secularizada e nos remete a uma estrutura de significado que se afirma de fora para dentro do campo religioso. Ou seja, peregrinação e romaria são categorias êmicas, usadas por peregrinos, romeiros e mediadores religiosos que se posicionam no campo religioso, ao passo que o turismo religioso é externo a essas categorias, sendo usado preferencialmente em contextos políticos-administrativos (Steil, 2003: 35).

A demarcação dos limites do que seja turismo religioso ou peregrinação, no entanto, é complexificada quando partimos de um contexto mais amplo de transformação do panorama religioso. A popularização do Caminho de Santiago de Compostela, conforme esboçamos anteriormente, esteve intimamente relacionada com um projeto de Estado do governo espanhol e com um esforço por parte de organizações civis dirigidas por peregrinos leigos. $\mathrm{O}$ que parece ficar patente, no caso de Santiago, é a perda do domínio sobre a peregrinação por parte da Igreja a partir do momento em que o Caminho passou a ser promovido por Associações civis espalhadas pelo mundo. $\mathrm{O}$ envolvimento de outros agentes como Organizações Não-Governamentais (ONGs), Associações, secretarias de turismo e prefeituras escancaram a formação de um contexto complexo em que turismo, espiritualidade e mercado aparecem como elementos intrincados (Steil e Carneiro, 2008). Deste modo, "a estrutura de significados religiosa" deixa de estar limitada às práticas inscritas no marco institucional, neste caso, da Igreja Católica e passa a estar presente em contextos tidos, $a$ priori,como seculares.

Para Steil, o que diferencia o turismo da peregrinação é:

o grau de imersão e de externalidade que cada uma dessas experiências pode proporcionar. Enquanto as peregrinações e romarias tendem a ser vistas como um ato religioso de imersão no sagrado, o turismo, mesmo quando 
adjetivado com religioso, caracteriza-se por uma externalidade do olhar, fundamental para que um evento possa ser considerado como turístico (Steil, 2003: 35).

Contudo, há uma série de transformações no panorama religioso que têm contribuído para que não apenas as experiências com o sagrado ocorram no plano da intimidade do sujeito, como também a certificação da verdade deixe de estar submetida a normalizações institucionalizadas, podendo ser atestada pelo próprio indivíduo. Essa desinstitucionalização da religião nos coloca novas questões e impossibilita a associação direta entre um evento religioso promovido pela igreja e a imersão no sagrado, bem como, entre um evento secular promovido por agentes laicos e a externalidade do olhar. Neste sentido, se as fronteiras entre o religioso e o não-religioso aparecem borradas, a definição de práticas como pertencentes a ordem do sagrado ou a ordem do turístico também tornam-se mais difusas.

Este tipo de problematização decorre do esgotamento de perspectivas analíticas dicotomizantes em que externo/interno, sagrado/profano, religioso/secular constituem-se como pólos distintos e capazes de dar conta de variados fenômenos a partir de uma chave heurística do tipo "ou é isto, ou aquilo". Tendo como referência empírica a prática de caminhadas promovidas pela ACASARGS, elaboro, a seguir, uma discussão inicial sobre o alcance do modelo dicotômico cotidiano/não-cotidiano como explicação plausível para o turismo.

\section{Turismo como a prática do não-coti- diano}

O esforço de conceitualização do turismo tem sido freqüente entre estudiosos do fenômeno e, de algum modo, tem acompanhado uma série de transformações epistemológicas das Ciências Sociais. Embora diversas, conforme os panoramas apresentados por Barretto (2000; 2003) e Silveira (2007), as definições inicialmente elaboradas podem ser descritas como conformando dois eixos explicativos. O primeiro deles recorria a elementos econômicos e infra-estuturais para definir o que seja turismo. A presença e atuação de agências e rede hoteleira, por exemplo, são definidoras, segundo tais conceitos, da existência do fenômeno. Outro eixo que podemos denominar de essencialista, conforme propõe Silveira (2007), concebe o deslocamento e o tempo de viagem como determinantes para caracterização do turismo.

Numa tentativa de problematizar estas perspectivas, alguns autores lançaram mão de definições que não concebiam o turismo a partir da presença de determinados serviços, mas a partir de um tipo de engajamento dos turistas. Conforme estas noções, o turismo se caracteriza a partir de oposições com o ordinário, com o trabalho, com o cotidiano e com a rotina (Smith, 1989; Graburn, 1989; Urry, 1990; Tuan, 1983).

John Urry, em seu livro sobre o Olhar do Turista (1990) expressa:

(...) torna-se necessário refletir sobre aquilo que produz um olhar turístico diferenciado. No mínimo deve haver alguns aspectos do lugar a ser visitado que o distinguem daquilo que é encontrado convencionalmente na vida cotidiana. O turismo resulta de uma divisão binária básica entre o ordinário/cotidiano e o extraordinário. As experiências turísticas envolvem algum aspecto ou elemento que induz experiências prazerosas, as quais, em comparação com o dia-a-dia, situam além do habitual. (...) No entanto, os objetos potenciais do olhar do turista precisam ser diferentes de algum modo. Precisam situar-se fora daquilo que é ordinário. As pessoas precisam vivenciar prazeres particularmente distintos, que envolvam diferentes sentidos, ou que se situem em uma escala diferente daquela com que se deparam em sua vida cotidiana (pp.28).

Desse modo, o "olhar turista" não se constitui como único, universal, presente em toda extensão social, mas sim como uma forma de apreciação definida, sobretudo, por meio do contraste com aquilo 
que é, para o turista, cotidiano. A constituição do "olhar do turista" depende, portanto, de experiências não-turísticas. Assim, é, justamente, a partir de uma relação contrastiva com aquilo que é habitual que práticas turísticas podem se inscrever na ordem do extraordinário. Se por um lado, a definição do turismo como um modo específico de engajamento, cristalizado em um tipo de "olhar", problematiza noções essencialistas e economicistas, por outro, ao recorrer ao contraste com o não-turismo, Urry dispersa a potência da análise do turismo como um fenômeno autônomo, tornando-o sempre atado ao seu estado contrastivo.

A emergência desse contraste com o que é rotineiro é o próprio ponto de partida para Nelson Graburn definir, em seu texto seminal "Turism: the sacred journey"(1989), o que seja turismo. Para Graburn, eventos turísticos se definem enquanto tais por sua característica de ser um não-trabalho, oposto daquilo que é diário. O tipo de perspectiva lançada por Graburn destaca os aspectos relacionais entre eventos turísticos com àquilo que é vivido no cotidiano e, portanto, regulado.

Tourism in the modal sense emphasized here is but one of a range of choices, or styles, of vacation or recreation - those structurally - necessary, ritualized breaks in routine tha define and relieve the ordinary (Graburn, 1989: 23).

Embora tenham proporcionado um avanço nos aportes teórico-metodológicos disponíveis para a compreensão do turismo, estas conceitualizações parecem encontrar seus limites quando se busca compreender, por exemplo, os resorts. Nestes espaços, o que está em jogo não é o exótico, mas uma projeção de um cotidiano estereotipado, padronizado, a imagem e semelhança dos países de origem do turista (Silveira, 2007:24).

As caminhadas promovidas pela ACASARGS, conforme procurararei apresentar, também conformam um contexto capaz de problematizar esta relação entre práticas turísticas e o não-cotidiano
A communitas como não-cotidiano: uma breve retomada dos aportes teóricos dos estudos sobre peregrinações e turismo religioso

No que se refere a produção dedicada às peregrinações e ao turismo religioso podemos dividir esses estudos, seguindo a proposta de Steil (2003), em três grandes correntes teóricas, das quais me deterei, especialmente, em uma delas. A primeira é o funcionalismo que predominou na análise destes eventos até meados da década de 1970. Segundo esta perspectiva, a peregrinação é um fenômeno religioso que exerce a função de aumentar a coerência e a integração cultural dos grupos. Esta visão é bastante referenciada pelas idéias durkheimianas sobre sociedade como um todo coerente, orgânico e ordenado, em alguma medida, por representações sociais que emergem de categorias religiosas.

A religião, para Durkheim (1996), não se definia a partir de entidades sobrenaturais, mas sim por meio da administração através de rituais daquilo que é sagrado e profano. Essa dualidade não se restringe apenas aos fenômenos religiosos como também ordena o social. Deste modo, as peregrinações são tomadas enquanto eventos unificadores do social e regeneradores da moral. Estudos como os de Spiro (1970), Marx (1977), Rabinow (1975) e Wolf (1958) são alguns dos trabalhos que seguem esta perspectiva.

A partir da década de 1960, os estudos de Victor Turner (1978; 1978b; 2008) romperam com as perspectivas funcionalistas que concebiam as peregrinações como eventos unificadores do social e regeneradores da moral. Assim, Turner afasta-se da proposta, desloca o interesse durkheimiano pelas coesões de um determinado grupo num contexto geográfico específico e passa a privilegiar as transformações, os processos pelos quais os eventos em questão atravessam.

Victor e Edith Turner (1978b) buscaram compreender as peregrinações cristãs a partir da análise de Van Gennep (1978) sobre os ritos de passagens. Estes ritos, que acompanham toda mudança de 
lugar, estado ou posição social, são constituídos por três estágios: separação, transição/liminaridade e agregação. Interessa a Turner, sobretudo, a liminaridade, um estado que é difícil de localizar numa rede de classificação porque está, justamente, num ponto que escapa às classificações, que foge às categorias estruturais empregadas. É nesse momento liminar que se estabelece, entre os neófitos, um clímax de camaradagem em que traços distintivos de status sociais anteriores ou vindouros, tais como roupas, insígnias e marcas, são apagados, os sujeitos se homogeneízam e um sentimento de igualitarismo desponta. Uma mistura de submissão e santidade, homogeneidade e camaradagem caracterizam o estado liminar que, por sua vez, conforma-se como um momento dentro e fora do tempo, dentro e fora da estrutura. Emerge, nesses contextos, o que Turner chama de communitas.

Com este conceito, Turner aponta para a existência de um constante tensionamento entre dois modelos de correlacionamento, dois modelos que se alternam e se justapõem: o primeiro é o de uma sociedade estruturada, com posições hierárquicas localizáveis e marcadas, o segundo modelo surge no período liminar e é caracterizado pela suspensão ou afrouxamento da estrutura o que gera uma extrema camaradagem aos sujeitos que aí se encontram, trata-se da communitas.

Para os indivíduos ou para os grupos, a vida social é um tipo de processo dialético que abrange a experiência sucessiva do alto e do baixo, de communitas e estrutura, homogeneidade e diferenciação, igualdade e desigualdade. A passagem de uma situação mais baixa para outra mais alta é feita através de uma linha de ausência de status (Turner, 1978, p. 122).

Este processo dialético ocorre entre termos interdenpendentes, ou seja, a relação entre estrutura e a communitas é dialética, uma não pode ocorrer sem a existência de outra. Não se trata, portanto, de uma relação entre termos diametralmente opostos, mas dialeticamente relacionados. Para Turner, numa estrutura $^{18}$ todos os indivíduos estão expostos, invariavelmente, à alternância desses estados. Eventos como peregrinação são, por sua natureza, fenômenos liminares que propiciam o surgimento da communitas.

O que sugiro é que a oposição entre cotidiano e não-cotidiano das análises do turismo, teve sua versão nos estudos sobre peregrinação e turismo religioso a partir do conceito de communitas. Nesse sentido, a liminaridade estrutural está no domínio do extraordinário, e as relações estruturadas correspondem ao ordinário. O efeito desta noção para os estudos sobre peregrinação foi deixar passar despercebido que as fronteiras e distinções sociais poderiam não ser suspensas nas peregrinações, conforme aponta a noção de communitas, mas mantidas e reforçadas (Eade e Sallnow, 1991; Coleman e Eade, 2004). A possibilidade de que a peregrinação não tenha este caráter extraordinário de suspensão estrutural fica ainda mais evidente em experiências como as das caminhadas promovidas pela ACASARGS em que não apenas está ausente o caráter antiestrutural, como o próprio passado único em Santiago é presentificado e vivido cotidianamente. A seguir procuro apresentar alguns dos dispositivos presentes nas caminhadas capazes de remeter os peregrinos à experiência no Caminho de Santiago.

\section{O caminho é aqui: a experiência de caminhar numa associação de pere- grinos}

Há uma espécie de perfil dominante no tipo de percurso das atividades promovidas pela ACASARGS. A maior parte das caminhadas ocorre em paisagens que reproduzem, em alguma medida, aquela experienciada em Santiago. Isto é, embora ocorram em diversos locais, as caminhadas da Associação têm duas características relativamente permanentes. A primeira delas é que todas são caminhadas em estradas rurais com poucos ou nenhum 
momento em que os peregrinos tenham que atravessar trilhas em mata fechada, por exemplo. Outra característica é que a maior parte dos trajetos percorridos estão entre 20 e 25 quilômetros de caminhada que é, propriamente, a média diária de quilômetros percorridos pelos peregrinos durante o Caminho espanhol.

Segundo os idealizadores da ACASARGS, no entanto, não basta que o lugar em que se caminha tenha similaridades com a Rota Jacobea, mas faz-se necessário também que o grupo crie determinadas estratégias que facilitem a referência à peregrinação.

Em uma caminhada promovida em Santo Antônio da Patrulha, cidade próxima a Porto Alegre, Fernanda, a presidente da ACASARGS, chamou a todos antes do início do trajeto para o interior de uma capela. Assim que entramos, ela iniciou, em bom espanhol, a oração do peregrino:

'Señor Jesucristo que sacaste a tu siervo Abrahan de la ciudad de Ur de los Caldeos guardándole en todas sus peregrinaciones y que fuiste el guía de pueblo hebreo a través del desierto. Te pedimos te dignes bendecir a estos hijos tuyos que por amor a tu nombre peregrinan a Compostela".Sé para ellos: compañeros en la marcha, guía en las encrucijadas, albergue en el camino, sombra en el calor, luz en la oscuridad, consuelo en sus desalientos y firmeza en sus propósitos; para que por tu guía lleguem incólumes al término de su camino y enriquecidos de gracias y de virtudes vuelvan ilesos a sus casas llenos de saludables virtudes" "Por Jesuscristo, nuestro Señor" "Marchad en nombre de Cristo que es Camino y rezad por nosotros em Compostela"

Ao final da oração perguntei a Marcos, um membro da diretoria da ACASARGS, porque fazer a oração naquele momento:

A Associação é para isso. A gente se esforça para que o peregrino relembre o que viveu em Santiago aqui conosco. Não é sempre que dá para ir pra Santiago e pra manter viva essa chama, a gente caminha aqui como se fosse lá. Claro que não é a mesma coisa, mas ajuda a manter viva a chama. E isso também é muito importante prá quem está se preparando pra ir pela primeira vez. Assim, a pessoa já se acostuma. A gente, da diretoria, podia caminhar em muitos lugares, sabe? Mas a gente se esforça para proporcionar essa sensação para o peregrino (Marcos, 42 anos).

Ao contrário de grupos de ecoturismo em que há um número limitado de vagas e em que o atendimento personalizado é um indicativo de bom serviço, nas atividades da ACASARGS, o sucesso dos passeios organizados é medido pela quantidade de inscritos, tendo como limite mínimo de participantes quarenta pessoas. As caminhadas do grupo ocorrem sempre em um único dia, normalmente domingo. Com um baixo custo, esses passeios conduzem peregrinos em ônibus cedidos, na maior parte das vezes, pelas prefeituras dos locais em que a caminhada será realizada. Pedro, um dos fundadores da ACASARGS e atual membro da diretoria, aponta sobre os objetivos mais gerais do grupo.

Nosso objetivo não é ganhar dinheiro, mas sim levar os peregrinos para caminhar. A gente tenta fazer parceria com as prefeituras, com as paróquias para elas darem para gente algum apoio, com um ônibus ou um café da manhã, por exemplo. Mas tudo isso é para baixar o preço, para que todo mundo possa caminhar. A gente não faz caminhada de dois dias porque o pessoal tem que trabalhar no sábado e porque, aí, já ia começar a ficar caro (Pedro, 33 anos).

Com uma média de setenta inscritos em cada caminhada, o grupo tem como ponto de encontro o centro de Porto Alegre de onde saem, normalmente, em dois ônibus seguidos por alguns carros de membros da diretoria. Tanto o trajeto de ida como o da volta são utilizados pelos coordenadores da ACASARGS para dar avisos e fazer propagandas de eventos que estejam relacionados com o Caminho de Santiago. Como pode ser notado neste trecho do diário de campo do dia 07 de julho de 2009. 
Antes mesmo do ônibus começar a andar, Fernanda, presidente da Associação, pegou um microfone e, pedindo a atenção de todos, deu o seguinte aviso: "Pessoal, como alguns de vocês já sabem, porque já avisamos na reunião de sábado, vai acontecer em setembro desse ano o primeiro curso de língua espanhola e de cultura do Caminho de Santiago de Compostela oferecido pela Universidade de Santiago de Compostela. [Nesse momento, algumas pessoas do ônibus começaram a aplaudir e assoviar]. Quem quiser ir tem que falar comigo até mês que vem. O Pedro vai distribuir agora um folheto pra cada um de vocês saberem do que se trata. Outra coisa, quem está indo pra Santiago no próximo mês aí? [quatro pessoas levantaram as mãos]. Eu trouxe a credencial do peregrino que, para quem não sabe, é o passaporte que o peregrino carimba durante o Caminho e marca os lugares por que passou. Quem estiver indo pode pegar ela comigo quando terminarmos a caminhada, a gente não cobra nada, só o custo da postagem, porque vem da Espanha, custa quatro reais.” Após Fernanda deixar o microfone, Marcos, membro da diretoria da ACASARGS e dono de uma editora que publica, exclusivamente, livros relacionados ao Caminho de Santiago tomou a palavra: "Olá escritores peregrinos, eu quero fazer um convite rápido pra vocês. Vocês sabem que nosso livro "Diários Peregrinos" esgotou rapidamente seus 1300 exemplares. Este livro tornou-se um marco na literatura peregrina porque teve características de antologia. Este livro registrou os desafios enfrentados pelos peregrinos que mostraram em seus relatos um mundo diferente, mais autêntico e mais natural que é o que vivemos em Santiago. Agora estamos com um novo trabalho, o livro "Relatos peregrinos" e vocês podem participar desse livro com quantas páginas quiserem. Pode ser foto, poema, relato, qualquer coisa. Quanto aos valores, são $\mathrm{R} \$ 70,00$ cada página, no mínimo de três páginas. Se vocês escreverem mais de dez páginas cai pra $\mathrm{R} \$ 60,00$. Vocês recebem três exemplares do livro por página que escrevem e ainda ganham uma Cruz de Santiago, exclusiva, banhada a ouro. Podem dividir o pagamento em quatro vezes. Quem se interessar, fala comigo" [Nota de 07 de julho de 2009].

O Caminho de Santiago é o assunto predominante durante as caminhadas promovidas pela ACASARGS. Embora seja abordado sob diversos aspectos, a referência ao Caminho é constante. Ela é, em geral, acionada por elementos que remetem a lembranças vividas durante a peregrinação à Santiago de Compostela. Em variadas ocasiões, ouvi referências, por exemplo, a uma árvore parecida com a que se viu durante a peregrinação, a uma bolha que surge no pé e no mesmo lugar de quando se fez o Caminho, ou mesmo à comida que, em Teutônia/RS, afirmava Paula, "é muito diferente de todas que tinha provado em Santiago".

Enquanto caminhavam, numa das atividades da ACASARGS, numa interminável subida, os peregrinos que já haviam ido à Santiago lembravam das dificuldades de atravessar, já no primeiro dia do Caminho, os Pirineus. Essas memórias são despertadas a cada reta, a cada novo detalhe que surge no ambiente em que se caminha. No meio de uma conversa que não era sequer sobre Santiago, uma peregrina afirma:

Essa estrada está muito parecida com uma região da Galícia na primavera.

Outra peregrina fala sobre como as caminhadas que faz com a ACASARGS se relacionam com suas experiências no Caminho:

Isso daqui me lembra muito de quando fiz o Caminho. É uma pena, mas acho que não vou voltar para lá tão cedo e para quem ficou, o Caminho tem que ser feito aqui mesmo.

A ambiência das caminhadas promovidas pela ACASARGS estabelecem uma 
significativa relação com a memória do peregrino, assumindo um sentido particular com a história do próprio indivíduo, presentificando seu passado em Santiago por meio do ambiente em que caminha no Brasil. A fala dos peregrinos que remete a possibilidade de se fazer o Caminho "aqui", conduz a reflexão acerca de um processo que consolidou Santiago não apenas como um local de peregrinação mas, sobretudo, como um tipo de experiência. Ao se colocar como divulgadora do Caminho no mundo as AACS têm divulgado uma sensibilidade, um modo de relação com o sagrado e com a paisagem, enfim, têm criado diversos Caminhos de Santiago.

\section{A caminhada como prática do espaço e de experiência temporal}

Na Atenas contemporânea, os transportes coletivos se chamam metaphorai. Para ir para o trabalho ou voltar para casa, toma-se uma "metáfora" um ônibus ou um trem. Os relatos poderiam igualmente ter esse belo nome: todo dia, eles atravessam e organizam lugares: eles os selecionam e os reúnem num só conjunto; deles fazem frases e itinerários. São percursos de espaços (De Certeau, 1994: 199).

Se a conseqüência mais evidente do que Michel De Certeau afirma é que as estruturas narrativas têm valores de sintaxes espaciais, também é verdadeiro que os deslocamentos no espaço adquirem valores narrativos. Ao se deslocarem, os caminhantes moldam espaços, seguem por trajetos já traçados, mas também podem subvertê-los e reorganizá-los. Para De Certeau, o ato de caminhar é um espaço de enunciação com uma tríplice função, em que cada um dos termos encontra paralelo com a língua: é um processo de apropriação do sistema topográfico pelo pedestre - assim como o locutor se apropria e assume a língua; é uma realização espacial do lugar - assim como o ato da palavra é uma realização sonora da língua; implica o estabelecimento de relações entre posições diferenciadas - assim como a língua coloca seus falantes em relação (De Certeau, 1994:177). As caminhadas dos pedestres tornam-se, conforme esta perspectiva, retóricas ambulatórias que moldam percursos como os falantes moldam frases.

Estas retóricas são formuladas, para De Certeau, a partir da articulação entre lugar e espaço. Lugar é aquilo que está estabelecido, a disposição das coisas conforme, por exemplo, o planejamento do trajeto elaborado pelos coordenadores da caminhada, já espaço é o lugar praticado, é o efeito da criatividade que desloca, transgride o que está prescrito. Neste sentido, o espaço está para o lugar assim como a língua falada está para a gramática.

Ao lançarmos mão do estabelecimento desta relação entre aqueles que falam e aqueles que caminham, passamos a nos balizar por uma espécie de sombra em que todas as funções e práticas do idioma encontram correspondentes no que De Certeau chama de retóricas ambulatórias. Por um lado, esta hipotética paridade permite que o ato ordinário de caminhar, de compor percursos adquira "dignidade de atenção", mas por outro, limita as múltiplas possibilidades de expressão deste ato como detentor de características específicas de manifestação, para além daquelas do idioma.

Bachelard, em "A poética do espaço" (1984), aponta para uma perspectiva que reconhece a importância desta relação entre sujeito e espaço sem, contudo, constrangê-la a uma referência lingüística. Para o autor, a imaginação trabalha nos espaços verdadeiramente habitados a partir de imagens capazes de ditar a dinâmica da relação entre passado, presente e futuro. O jogo temporal se dá a partir de uma espacialidade que não designa apenas um ambiente exterior ao sujeito, mas que o inclui, uma vez que a imagem, o espaço e o tempo não se dão nem no sujeito, nem fora dele, mas a partir da relação.

Aqui o espaço é tudo. Porque o tempo não mais anima a memória. A memória - coisa estranha! - não registra a duração concreta, a duração no sentido 
bergsoniano. Não se podem reviver as durações abolidas. Só se pode pensá-las na linha de um tempo abstrato privado de toda densidade. É pelo espaço, é no espaço que encontramos os belos fósseis de uma duração concretizados em longos estágios (Bachelard, 1984:203).

Assim, é na medida em que estabelecemos relações, constituímos histórias, e percorremos o espaço, que ele toma forma. Trata-se de concebê-lo não mais como externo aos Humanos, mas como constitutivo das dinâmicas sociais e temporais daqueles que o habitam, bem como constituído pelas relações nele engajadas, tornando-se, num jogo relacional, modificador das práticas nele produzidas, mas também modificado por elas.

A projeção de um lugar para caminhar, por parte dos organizadores da caminhada, que fosse capaz de remeter o peregrino à Santiago, e a prática de um espaço por parte dos caminhantes, coloca em evidência não apenas a relação intrínseca e indistinta entre um sujeito que habita e um mundo que é habitado, como também evidencia a multiplicidade de imagens, no sentido bachelardiano, que as ações em torno de uma caminhada - seja de elaboração do trajeto, seja de sua feitura - comportam. Isto é, a elaboração de um trajeto no Brasil que presentifique o passado em Santiago é possível na medida em que os espaços em que se caminha, podem ser experimentados de maneiras distintas. Determinados artifícios como fazer a oração do peregrino como se faz em Santiago, espalhar setas amarelas para indicar o caminho como em Santiago e caminhar por paisagens e distâncias como em Santiago, sugerem uma experiência específica.

A caminhada - seja no Brasil seja em Santiago -, conforme a concebo, promove este deslocamento, tanto objetivo como subjetivo, e o que interessa aqui talvez não seja nem um e nem outro como elementos autônomos, mas enquanto relacionados. Flaneurs, voyeurs, peregrinos, caminhantes não são denominações que se constituem enquanto tal por conta de um território privilegiado a cada um deles, mas na medida em que os espaços são mobilizados subjetivamente de maneiras específicas. Este tipo de perspectiva nos coloca diante de outro horizonte de questões em que o que está em jogo é a experiência do turista e o modo pelo qual ele articula elementos como tempo, espaço e subjetividade. Trata-se de buscar perceber sua experiência como resultado de um arranjo relacional entre uma série de dimensões e não de partir de um a priori em que esta experiência já está circunscrita numa única possibilidade, neste caso, a do não-cotidiano.

\section{Bibliografia:}

Bachelard, Gaston

1984 A poética do espaço A poética do espaço. São Paulo: Martins Fontes.

Barretto, Margarita.

2000 "As ciências sociais aplicadas ao turismo". In Serrano, Célia; Bruhns, Heloísa T.; Luchiari, M. Tereza. (org.). Olhares contemporâneos sobre o turismo. Campinas: Papirus, (pp. 1736)

2003 "O imprescindível aporte das ciências sociais para o planejamento e a compreensão do turismo". In Horizontes Antropológicos, Porto Alegre, (20):15-30).

Carneiro, Sandra de Sá.

2007 A pé e com fé: brasileiros no Caminho de Santiago. São Paulo: CNPq/ Pronex: Attar.

Coleman, Simon e Eade, John.

2004 Reframing pilgrimage: cultures in motion. London/ New York: Routledge

De Certeau, Michel

1994 A invenção do cotidiano: artes de fazer. Petrópolis:Vozes.

Dupront, Alphonse.

1987 Du Sacré. Paris: Gallimard.

Durkheim, Emile.

1996 As formas elementares da vida religiosa. São Paulo: Martins Fontes.

Eade, John e Sallnow, Michael (eds)

1991 Contesting the Sacred: the Antropology of christian pilgrimage. London and New York, Routledge.

Frey, Nancy Louise.

1998 Pilgrim Stories: on and off the 
road to Santiago. California: University of California Press.

Graburn, Nelson.

1989 "Tourism: the sacred journey". In Smith, V. (ed.). Hosts and guests: the anthropology of touris : 21-36. Philadelphia: University of Pennsylvania Press.

Marx, Emanuel

1977 "Communal and individual pilgrimage: the region of saints tombs in South Sinai". In Werbner, R. P. (eds) Regional cults. London: London Academic Press

Rabinow, Paul

1975 Symbolic domination: cultural form and historical change in Morocco. Chicago: University of Chicago Press

Smith, Valene (ed.).

1989 Hosts and guests: the anthropology of tourism. Philadelphia: University of Pennsylvania Press.

Steil, Carlos Alberto.

2003 "Peregrinação, romaria e turismo religioso: raízes etimológicas e interpretações antropológicas". In Abumanssur, Edin Sued. (org.). Turismo religioso: ensaios antropológicos sobre religião e turismo: 29-52. Campinas: Papirus.

Steil, Carlos Alberto e Carneiro, Sandra de Sá.

2008 Peregrinação, turismo e nova era: Caminhos de Santiago de Compostela no Brasil. Religião e Sociedade, 28(1):108-124.

Silveira, Emerson

2007 Por uma Sociologia do Turismo. Porto Alegre: Zouk.

Spiro, Melford E.

1970 Budhism and society: a great tradition and its burmese vicissitudes. New York, Harper \& Row.

Toniol, Rodrigo; Steil, Carlos Alberto.

2010 Ecologia, Nova Era e Peregrinação: uma etnografia da experiência de caminhadas na Associação dos Amigos do Caminho de Santiago de Compostela do Rio Grande do Sul. In Debates do NER, 17:97-120).

Tuan, Yi-Fu.

1983 Espaço e Lugar: a perspectiva da ex- periência. São Paulo: Difel.

Turner, Victor.

1978 O processo ritual : estrutura e antiestrutura. Petropolis: Vozes.

Turner, Victor.

1978b Image and Pilgrimage in Christian Culture. New York, Columbia University Press.

2008 Dramas, campos e metáforas: ação simbólica na sociedade humana. Niterói: Ed. UFF.

Urry, John

1990 The tourist gaze. Leisure and travel in contemporary societies. London: Sage.

Van Gennep, Arnold

1978 Os ritos de passagem. Petrópolis: Vozes

Wolf, Eric

1958 The Virgin of Guadalupe: a Mexican national symbol. Journal of American Folklore 71(1): 34-39.

\section{NOTAS}

1 Uma primeira versão deste trabalho foi apresentada na $27^{\mathrm{a}}$. Reunião Brasileira de Antropologia, realizada entre os dias 01 e 04 de agosto de 2010, Belém, Pará, Brasil. Agradeço aos comentários de Carlos Alberto Steil, Margarita Barretto, Álvaro Banducci Júnior e Rodrigo Grünewald.

2 Trata-se de um símbolo do Caminho de Santiago muito difundido entre os peregrinos. Sua origem é pagã e, durante a Idade média, era usada entre os cristãos como forma de identificação.

3 Sandra de Sá Carneiro propõe uma divisão em seis fases histórica do Caminho de Santiago. "A primeira fase vai do descobrimento do sepulcro até meados do século $\mathrm{X}$, em que se iniciam as peregrinações a partir dos países estrangeiros; A segunda fase vai desde esse momento até o século XI, quando se entra na segunda fase de formação ou expansão do fenômeno; A terceira fase abrange os séculos XII, XIII e XIV, que constituem o esplendor das peregrinações jacobeas; A quarta fase está situada entre meados do século XIV até princípios do século XVI, esta é a fase mais crítica do fenômeno; A quinta fase vai desde o século XVI até praticamente o século XX; A sexta fase situa-se no século XX, quando começa o processo de revitalização sob novos padrões simbólicos, religiosos, sociais e culturais” (Carneiro, 2007: 66)

4 Um dos principais livros que promoveram o Caminho de Santiago no mundo foi o "Diário de um 
Mago" de Paulo Coelho, publicado pela primeira vez em 1987 e traduzido para 21 línguas.

5 Rota Jacobea é o nome como era conheci o Caminho de Santiago durante a Idade Média. Assim ficou conhecida a rota de peregrinação após o papa Calixto II, no século XIII, considera-la uma forma de obtenção de indulgência plenária. Os termos Rota Jacobea e Caminho de Santiago são usados, atualmente, como sinônimos.

6 A Xunta de Galícia é um colegiado do governo da Galícia responsável por promover as atividades relacionadas ao Caminho de Santiago que são de interesse da província espanhola.

7 Oficina de peregrinaciones é uma organização que tem como objetivos, segundo o site www.peregrinando.org, "conservar, proteger e fomentar o Caminho de Santiago e coordenar o voluntariado, ampliando-o ao Brasil, Itália e outros países, criando assim uma rede de Voluntários para a execução de todos os fins e objetivos de seus estatutos".

8 Fonte: http://www.santiago.org.br/ (consultado em 15/08/2009)

9 Fonte: http://www.santiago.org.br/ (consultado em 15/08/2009)

10 Fonte: http://www.santiago.org.br/ (consultado em $15 / 08 / 2009$ )

11 Existem, ao menos, nove rotas que levam a Igreja de Santiago de Compostela, sendo a mais popular entre os brasileiros o Caminho Francês.

12 Estas dicas vão desde longas discussões a respeito de que calçado usar, ou quantas calças levar até albergues que se deve ficar e pessoas que se deve procurar.

13 A compostelana é um documento fornecido pela Igreja que certifica a realização da peregrinação. Para recebê-la o peregrino precisa: apresentar um documento chamado credencial do peregrino que comprova os locais em que se passou durante a peregrinação, dizer que uma das razões para a realização da peregrinação foi religiosa e provar que percorreu os últimos $100 \mathrm{Km}$, para os que estão a pé, e $200 \mathrm{Km}$, para os que estão de bicicleta ou a cavalo, sem auxílio de transportes motorizados

14 Os valores em dólares seria entre U\$22.00 e U\$ 32.00

15 www.santiagoperegrino.com.br

16 Fonte: http://www.santiagoperegrino.com.br/ (consultado em 15/08/2009)
17 Fonte: http://www.santiago.org.br/ (consultado em 15/08/2009)

18 Turner define estrutura como "arranjos padronizados de conjuntos de papéis, conjuntos de posições e seqüências de posições reconhecidas conscientemente e operado regularmente em uma sociedade determinada e intimamente ligados a normas e sanções locais e políticas" (Turner, 2008:221)
Recibido:

Reenviado:

Aceptado:

$18 / 08 / 2010$

$27 / 09 / 2010$

$05 / 12 / 2010$

Sometido a evaluación por pares anónimos 